\title{
ANALISA KELAYAKAN USAHA MIKRO KECIL DAN MENEGAH (UMKM) UNTUK PRODUK KRASIDA PADA PT. PEGADAIAN MENGGUNAKAN METODE J48.
}

\section{LISWATI SITUMORANG}

\author{
Program Studi Teknik Informatika STMIK Budi Darma, Medan, Indonesia \\ Email: Liswatisitumorang95@gmail.com
}

\begin{abstract}
Abstrak
Saat ini dalam dunia banyaknya data yang berlimpah dan berkelanjutan bisa dimamfaatkan dalam data mining dalam rangka pengelolaan yang lebih baik dalam pelaksanaan analisa kelayakan Usaha Mikro Kecil Menegah (UMKM) untuk produk krasida pada Pt. Pegadaian yang lebih efektif penelitian ini dilakukan untuk memamfaatkan dayang yang ada sebagai sumber informasi strategis bagi pelaku UMKM. Dalam pengolahan data UMKM dan mengklasifikasi masa kelayakan untuk produk krasidan untuk menggunakan tehnik data mining. Klasifikasi masa kelayakan terhadap rekrutmen UMKM menggunakan metode J48 . atribut yang digunakan terdiri dari golongan usaha yang dimiliki calon nassabah, tinggi rendahnya jumlah penjualan terhadap masa yang akan datang adalah rata rata yang dibutuhkan UMKM.Dalam skripsi ini perangkat lunak yang digunakan adalah Weka. Dengan demikian interpretasihasil penelitian mengindikasikan bahwa variabel yang perlu digunakan sebagai pertimbangan dilakukan analisa kelayakan UMKM.
\end{abstract}

Kata kunci: Datamining, UMKM, Krasida, Metode J48, Weka

\section{Abstrak}

Currently, in the world of abundant and sustainable data, it can be utilized in data mining in order to better manage the feasibility analysis of Medium-Scale Micro Enterprises (UMKM) for the kraside products at Pt. A more effective pawnshop this research was conducted to utilize existing court ladies as a source of strategic informationfoUMKM In processing UMKM data and classifying the feasibility period for krasidan products to use data mining techniques. The eligibility period for UMKMrecruitment uses the J48 method. the attributes used consist of business groups owned by prospective nassabah, the high or low number of sales in the future is the average needed by UMKM.In this thesis the software used is Weka. Thus the interpretation of the results of the study indicates that the variables that need to be used as considerations are analyzed for the feasibility of UMKM.

Kata kunci : Datamining, UMKM, Krasida, Metode J48, Weka

\section{Pendahuluan}

Produk Krasida adalah kredit angsuran yang diberikan kepada usaha mikro kecil dan menegah untuk pengembangan usaha dengan sistem gadai. Krasida merupakan program pemerintah untuk membantu badan usaha, solusi terpercaya untuk mendapatkan solusi yang tercepat, mudah dan murah. Agunan berupa perhiasan emas dan kendaraan bermotor. Data Mining adalah sebagai proses untuk mendapatkan informasi dari gudang basis data yang besar. Data mining juga dapat diartikan sebagai peng ekstrakan informasi baru yang diambil dari bongkahan data besar yang dapat membantu dalam pengambilan keputusan dengan tehnik menelusuri data yang ada untuk membantu sebuah model, kemudian model tersebut agar dapat mengenali pola yang lain yang tidak ada dalam basis data yang tersimpan Algoritma J48 dalam klasifikasi sebagai teknik dalam data mining yang digunakan dalam penelitian. Dengan menggunakan algoritma J48 penulis lebih mengerti dan lebih mudah memahami dalam menyelesaikan analisa kelayakan usaha mikro kecil menegah, dengan pengelompokkan ini akan mempermudah manajemen dan pengawasan untuk melihat apakah nasbah sanggup melakukan pembayaran angsuran kredit. Teknik decision tree lebih fleksibel dan membuat metode ini atraktif, khususnya karena memberikan keuntungan berupa fisualisasi saran dalam bentuk decision tree sehingga prosedur klasifikasinya dapat diamati. Untuk mengatasi masalah diatas, perlu digunakan algoritma dalam data mining dengan memamfaatkan data data untuk uji kelayakan.

\section{TEORITIS}

\subsection{Data Mining}

Data mining adalah proses yang mempekerjakan satu atau lebih tehnik pembelajaran komputer (machine learning) untuk menganalisis dan mengekstraksi pengetahuan (Knowledge) secara otomatis. Defenisi lain adalah pembelajaran bebasis induksi (introduction- based learning) adalah proses pembentukan defenisi-defenisi konsep umum yang dilakukan dengan cara mengobservasi contoh contoh spesifik dari konsep yang akan dipelajari. Knowledge Discovery in Database (KDD), adalah penerapan kode saintifik pada data mining

Data mining merupakan proses iteratif dan interaktif untuk menemukan pola atau model baru yang sempurna bermamfaat dan dapat dimengerti dalam suatu database yang sangat besar (massive database) .

1. Sahih : Dapat digeneralisasikan untuk masa yang akan datang.

2. Baru : Apa yang sedang tidak diketahui

3. Bermamfaat : Dapat dingunakan untuk melakukan suatu tindakan .

4. Iteratif : memerlukan sejumlah proses yang diulang

5. Interaktif : memerlukan interaksi manusia dalam prosesnya. 
Data mining berisi pencarian trend atau pola yang di inginkan dalam data base besar untuk membantu pengambilan keputusan di waktu yang akan datang. Pola pola ini dikenali oleh perangkat tertentu yang dapat memberikan siatu analisa data yang berguna dan berwawasan yang kemudian dapat di pelajari dengan lebih teliti, yang mungkin saja menggunakan perangkat pendukung keputusan yang lainya [1].

Data mining bukanlah suatu bidang yang sama sekali baru. Salah satu kesulitan untuk mendefinisikan data mining adalah kenyataan bahwa data min

ng mewariskan banyak aspek dan teknik bidang-bidang ilmu yang sudah mapan terlebih dahulu. Data mining memiliki akar panjang dari ilmu seperti ilmu kecerdasan buatan (artificial intelligent), maching learning, statistic, database, dan juga informasi retrievel.

\subsection{Produk}

Produk adalah sesuatu yang dapat ditawarkan ke pasar untuk diperhatikan, dipakai, dimiliki, atau dikonsumsikan sehingga dapat memuaskan keinginan atau kebutuhan [5] Dari pengertian ini dapat disimpulkan bahwa hampir semua yang termasuk produksi adalah benda nyata yang dapat dilihat, diraba, dan dirasakan. Produk adalah segala sesuatu yang dapat ditawarkan kepada pasar untuk memuaskan suatu keinginan atau kebutuhan, termasuk barang fisik, jasa, pengalaman, acara, orang, tempat, properti, organisasi, informasi, dan ide [6].

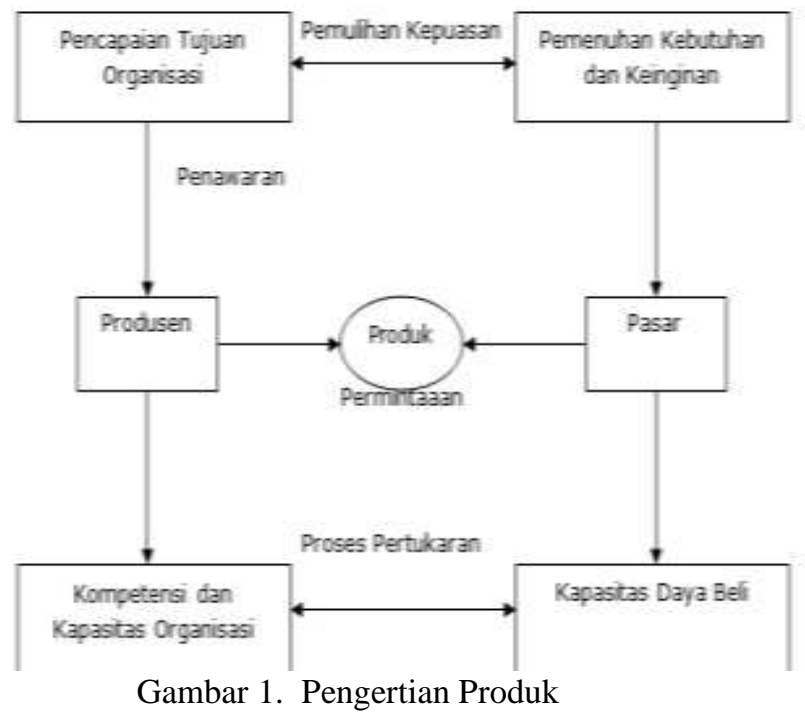

Sumber: Marketing manajement(2013) [6]

\subsection{Algoritma J48}

Decision tree $\mathrm{J} 48$ merupakan implementasi dari algoritma $\mathrm{C} 4.5$ yang memproduksi decision tree. Ini merupakan standar algoritma yang digunakan dalam machine learning. Decision tree merupakan salah satu algoritma klasifikasi dalam data mining. Algoritma klasifikasi merupakan algoritma yang secara induktif dalam pembelajaran dalam mengkonstruksikan sebuah model dari dataset yang belum diklasifikasikan (pre classified dataset). Setiap data dari item berdasarkan dari nilai dari setiap atribut. Klasifikasi dapat dilihat sebagai mapping dari sekelompok set dari atribut dari kelas tertentu. Decision tree mengklasifikasikan data yang diberikan menggunakan nilai dari atribut. Dataset dengan atribut pilihan kemudian diklasifikasikan menggunakan decision tree J48 [7].

Decision Tree J48 merupakan implementasi algoritma C4.5 (berbasis Java) pada Weka. Algoritma C4.5 digunakan untuk pemisah obyek. Tree atau pohon keputusan banyak dikenal sebagai bagian dari Graph, yang termasuk dalam irisan bidang ilmu otomata dan teori bahasa serta matematika diskrit. Tree sendiri merupakan graf tak-berarah yang terhubung, serta tidak mengandung sirkuit.

Secara umum algoritma C4.5 untuk membangun pohon keputusan adalah sebagai berikut:

1. Pilih atribut sebagai akar

2. Buat cabang untuk tiap-tiap nilai

3. Bagi kasus dalam cabang

4. Ulangi proses

Untuk setiap cabang sampai semua kasus pada cabang memiliki kelas yang sama. Untuk memilih atribut sebagai akar, didasarkan pada nilai gain tertinggi dari atribut-atribut yang ada. Untuk menghitung gain digunakan persamaan sebagai berikut:

$\operatorname{Gain}(\mathrm{S}, \mathrm{A})=\operatorname{Entropy}(S)-\sum^{n} \operatorname{Entropy}(\mathrm{Si})$

Keterangan:

$\mathrm{S} \quad=$ himpunan kasus

$\mathrm{A}=$ atribut 
$\mathrm{n} \quad=$ jumlah partisi atribut $\mathrm{A}$

$|\mathrm{Si}|=$ jumlah kasus pada partisi ke-i

$|\mathrm{S}| \quad=$ jumlah kasus dalam $\mathrm{S}$

Rumus dasar dari entropy tersebut adalah sebagai berikut:

$\operatorname{Entropy}(S)=\sum_{i-1}^{n}-\mathbf{p i} * \log 2$ pi

Keterangan:

$\mathrm{S} \quad=$ himpunan kasus

A $=$ fitur

$\mathrm{n} \quad=$ jumlah partisi $\mathrm{S}$

pi $\quad=$ proporsi dari Si terhadap $S$

\section{ANALISA DAN PEMBAHASAN}

\subsection{Analisa}

Algoritma J48 merupakan algoritma yang digunakan untuk membentuk pohon keputusan. Sedangkan pohon keputusan merupakan representasi sederhana dari teknik klasifikasi untuk sejumlah kelas dimana simpul internal maupun akar ditandai dengan nama atribut, rusuk-rusuknya diberi label nilai atribut dan simpul daun ditandai dengan kelas-kelas yang berbeda. Pohon keputusan dapat membagi kumpulan data yang besar menjadi himpunan-himpunan record yang lebih kecil dengan menerapkan serangkaian aturan keputusan. Hasil pohon keputusan yang dihasilkan dari algotitma J48 dapat digunakan sebagai bahan acuan untuk memprediksi dampak dari persyaratan yang telah dibuat.

Adapun dasar dari algoritma J48 adalah sebagai beriku :

1. Membangun dicision tree dari training set.

2. Melakukan pruning untuk menyederhanakan tree.

3. Mengubah tree yang dihasilkan dalam beberapa rule.jumlah rule sama dengan jumlah path yang mungkin didapat dari root sampai leaf node.

Adapun analisa yang dilakukan berdasarkan data-data yang ada pada kantor Pegadaian UPC Kampung durian, Medan, dimana data-data Nassabah UMKM yang diambil secara acak pada tahun 2018. Dimana data-data Nassabah UMKM yang digunakan untuk menganalisa beberapa data beserta atributnya. Berikut ini adalah data UMKM yang mengajukan pinjaman Pada Produk Krasida tahun 2018.

\subsection{Pembahasan}

Algoritma J48 adalah salah satu jenis classifier pada metode klasifikasi dalam data mining dan bagian dari C4.5 decision tree yang sederhana. C4.5 membangun sebuah pohon keputusan berdasarkan pada seperangkat input data yang berlabel. Pohon keputusan adalah model prediksi yang digunakan struktur pohon atau struktur berhirarki. Konsep dari pohon keputusan adalah mengubah data menjadi pohon keputusan dan aturan-aturan keputusan.

\begin{tabular}{|c|c|c|c|c|c|c|c|c|c|}
\hline \multicolumn{10}{|c|}{ Data Nasabah Pengajuan UMKM Pada Produk Krasida } \\
\hline \multicolumn{10}{|c|}{ PT. Pegadaian UPC Kampung Durian } \\
\hline \multicolumn{10}{|c|}{ Pada Tahun 2018} \\
\hline No & NamaUsaha & Berkas & Jumlah Pinjaman & Penghasilan/bln & Jenis Usaha & Agunan/Jaminan & Produk & Keputusar & Status Usaha \\
\hline 1 & RumbiaCoffe & Kartu Keluarga & RP $50.000 .000,00$ & Rp $6.000 .000,00$ & Kuliner & BPKB & Krasida & Diterima & Aktif \\
\hline 2 & The Gamis & Suratlzin Usaha & RP $80.000 .000,00$ & Rp $10.000 .000,00$ & Desain & Surat lzin Usaha & Krasida & Diterima & Aktif \\
\hline 3 & Royal Apartemen & Suratlzin Usaha & Rpo $100.000 .000,00$ & Ro $15.000,000,00$ & Bisnis & Surat Tanah & Krasida & Diterima & Aktif \\
\hline 4 & matrix's ben & SIM & Rp90.000,000,00 & Rp $50.000,000,00$ & Bisnis & Emas & Krasida & Tolak & Aktif \\
\hline 5 & A'ys seafood & Kartu Keluarga & $\operatorname{Ro} 60.000,000,00$ & Ro7.000,000,00 & Kuliner & Sertifikat Rumah & Krasida & Tolak & Aktif \\
\hline 6 & Coffe Jogal & PASPOR & RP $80.000 .000,00$ & $\operatorname{Ros} 8.000 .000,00$ & Kuliner & Sertifikat Rumah & Krasida & Diterima & Aktif \\
\hline 7 & Jade Restourant & Suratlzin Usaha & RP $80.000,000,00$ & Rpg.000,00,00 & Kuliner & Surat lain Usaha & Krasida & Diterima & Aktif \\
\hline 8 & Kalista & SIM & Rp $100.000 .000,00$ & Rp6.000.000,00 & Fotocopy & Surat Tanah & Krasida & Tolak & Aktif \\
\hline 9 & Kebaya & Kartu Keluarga & Ro $150.000 .000,00$ & Rp4.500.000,00 & Desain & agunan/Jaminan & Krasida & Tolak & Aktif \\
\hline 10 & UD. Bolive & Suratlzin Usaha & Rp $70.000 .000,00$ & Rp3.000.000,00 & Grosir & Sertifikat Rumah & Krasida & Tolak & Aktif \\
\hline 11 & H\&R Tour & SIM & $\operatorname{Rp} 80.000,000,00$ & $\operatorname{Ro5} 5.500 .000,00$ & Bisnis & Emas & Krasida & Tolak & Aktif \\
\hline 12 & Misoup Kampung & SIM & Ro150.000.000 & $\operatorname{Rp} 6.000,000,00$ & Kuliner & BPKB & Krasida & Tolak & Aktif \\
\hline 13 & Glend's Bordir & PASPOR & $R p 200.000 .000$ & Ros.000,000,00 & Desain & Surat lzin Usaha & Krasida & Tolak & Aktif \\
\hline 14 & Green's Bordir & Kartu Keluarga & $\operatorname{Rp} 100.000 .000$ & Ro $10.000,000,00$ & Desain & Sertifikat & Krasida & Diterima & Aktif \\
\hline 15 & UD.Prima & Suratlzin Usaha & $\operatorname{Rp} 45.000 .000$ & $\mathrm{Rp} 7.500 .000,00$ & Grosir & Emas & Krasida & Diterima & Aktif \\
\hline
\end{tabular}

Gambar 2. Data nassabah Pengajuan UMKM Pada Produk Krasida PT. Pegadaian UPC Kampung Durian

\subsection{Pre-Procesing Data}

Algoritma J48 merupakan algoritma yang digunakan untuk membentuk pohon keputusan. Sedangkan pohon keputusan dapat diartikan suatu cara untuk memprediksi atau mengklarifikasi yang sangat luas. Pemrosesan data 
mining menggunakan algoritma J48 dengan melakukan pengumpulan data dan mengklasifikasikan data menggunakan representasi struktur pohon keputusan dimana setiap node mempresentasikan nilai dari atribut dan daun mempresentasikan node. Data yang dimiliki akan disusun menjadi sebuah tabel dan jumlah responden sebelum dilakukan perhitungan untuk mencari nilai entropy dan gain. Adapun tahap yang digunakan pada algoritma J48 adalah :

1. Pilih atribut sebagai akar.

2. Buat cabang untuk tiap-tiap nilai.

3. Bagi kasus dalam cabang.

Ulangi proses untuk setiap cabang sampai semua kasus pada cabang memiliki kelas yang sama.

Sebelum melakukan pembahasan dengan Algoritma J48, pertama kali dilakukan pre-procesing, pre-procesing data merupakan langkah yang digunakan untuk pengujian yang akan dijalankan. Dalam pre-procesing salah satu langkah yang digunakan adalah transformasi setiap nilai atribut yang sama kebentuk numerik sehingga mudah dilakukan untuk proses pemecahan masalah dan bentukan data dan sampelnya. Berikut ini pre-procesing yang dilakukan data ujinya yaitu :

Langkah-langkah algoritma decision tree J48 dalam melakukan proses data mining adalah sebagai berikut : Mengelompokkan setiap variabel untuk mendapatkan atribut yang akan digunakan untuk menghitung entropy dari kasus agar mendapatkan akar dan cabang dari data nasabah. Dalam tahap ini juga tahap klasifikasi pada data mining dilakukan, dimana data tersebut dikelompokkan dan diklasifikasikan berdasarkan variabel-variabel yang telah dilakukan. Berikut ini adalah klasifiksi data berdasarkan gambar 2.

Tabel 1. Pengelompokan Jumlah Pinjaman

\begin{tabular}{lll}
\hline No & Pengelompokan Jumlah Pinjaman & Keterangan \\
\hline 1 & $>100 \mathrm{jt}$ & Besar \\
2 & $50-99 \mathrm{jt}$ & Sedang \\
3 & $<50 \mathrm{jt}$ & Kecil \\
\hline
\end{tabular}

Tabel 2. Pengelompokan Jumlah Penghasilan

\begin{tabular}{lll}
\hline No & Pengelompokan Jumlah penghasilan & Keterangan \\
\hline 1 & $>=10 \mathrm{jt}$ & Besar \\
2 & $5-9,9 \mathrm{jt}$ & Sedang \\
3 & $<5 \mathrm{jt}$ & Kecil \\
\hline
\end{tabular}

\begin{tabular}{|c|c|c|c|c|c|c|c|c|c|}
\hline \multicolumn{10}{|c|}{ Data Nassabah Pengajuan UMKM Pada ProdukKrasida } \\
\hline \multicolumn{10}{|c|}{ PT. Pegadaian UPC Kampung Durian } \\
\hline \multicolumn{10}{|c|}{ Pada Tahun 2018} \\
\hline No & NamaUsaha & Berkas & Jumlah Pinjaman & Pengharilan/bln & Jenis Usaha & Agunan/Jaminan & Produk & Ke putusan & Status Usah \\
\hline 1 & Rumbia Coffe & Kartu Keluarg & Sedang & Sedang & Kuliner & $B P K B$ & Krasida & Ditenima & Alcif \\
\hline 2 & The Gamis & Surat lzin Usaha & Sedang & Besar & Desain & Surat lzin Usaha & Krasida & Diterima & Alkif \\
\hline 3 & Royal Apartemen & Surat lzin Usaha & Besar & Besar & Bisnis & Surat Tanah & Krasida & Diterima & Alcif \\
\hline 4 & matrix's ben & $5 \mathrm{M}$ & Sedang & Sedang & Bisnis & Emas & Krasida & Tolak & Alcif \\
\hline 5 & Ayss seafood & Kartu Keluarga & Sedang & Sedang & Kuliner & Sertifikat Rumah & Krasida & Tolak & Alcif \\
\hline 6 & Coffe Jogal & PASPOR & Sedang & Sedang & Kuliner & Sertifikat Rumah & Krasida & Diterima & Alkif \\
\hline 7 & Jade Restourant & Surat lzin Usaha & Sedang & Sedang & Kuliner & Surat lzin Usaha & Krasida & Diterima & Alcif \\
\hline 8 & Kalista & SIM & Besar & Sedang & Fotocopy & Surat Tanah & Krasida & Tolak & Alcif \\
\hline 9 & Kebaya & Kartu Keluarg & Besar & Kecil & Desain & agunan/Jaminan & Krasida & Tolak & Alkif \\
\hline 10 & UD. Bolive & Surat lzin Usaha & Sedang & Keoil & Grosir & Sertifikat Rumah & Krasida & Tolak & Alkif \\
\hline 11 & H\&R Tour & $5 \mathrm{M}$ & Sedang & Sedang & Bisnis & Emas & Krasida & Tolak & Alcif \\
\hline 12 & Misoup Kampung & $5 \mathrm{M}$ & Besar & Sedang & Kuliner & $B P K B$ & Krasida & Tolak & Alkif \\
\hline 13 & Glend's Bordir & PASPOR & Besar & Sedang & Desain & Surat lzin Usaha & Krasida & Tolak & Alcif \\
\hline 14 & Green's Bordir & Kartu Keluargo & Besar & Besar & Desain & Sertifikat & Krasida & Diterima & Alcif \\
\hline 15 & UD.Prima & Surat lzin Usaha & Keoll & Sedang & Grosir & Emas & Krasida & Diterima & Alkif \\
\hline
\end{tabular}

Gambar 3. Pengelompokan Jumlah Pinjaman

\subsection{Pilih Atribut Akar}

Untuk pemilihan atribut sebagai akar, didasarkan pada nilai gain tertinggi dari atribut-atribut yang ada dengan menggunakan dua persamaan maka akan didapatkan entropy dan gain yang digunakan sebagai akar dalam membuat pohon keputusan.

Maka, berikut ini penyelesaian perhitungan nilai entropy:

1. Entropy Total 
Untuk menggunakan dua persamaan Nilai Entropy berdasarkan penilaian keseluruhan data berdasarkan tabel Data Nassabah Pengajuan UMKM pada Produk Krasida.

Diketahui :

Nilai Objek Keseluruhan $(\mathrm{Si})=15$

Nilai Atribut Hasil (Diterima) $=7$

Nilai Atribut Hasil (Ditolak) $=8$

Entropy Total

$$
\begin{aligned}
& =\sum_{i-\mathbf{1}}^{n}-\mathbf{p i} * \log \mathbf{2} \mathbf{p i} \\
& =\left(-\frac{7}{15} * \log 2\left(\frac{7}{15}\right)\right)+\left(-\frac{8}{15} * \log 2\left(\frac{8}{15}\right)\right) \\
& =0.5856817682
\end{aligned}
$$

1. Menghitung nilai Entropy Berkas

a. Entropy Surat Izin Usaha

$$
\begin{aligned}
& =\left(-\frac{4}{5} * \log 2\left(\frac{4}{5}\right)\right)+\left(-\frac{1}{5} * \log 2\left(\frac{1}{5}\right)\right) \\
& =0,721885
\end{aligned}
$$

b. Entropy Kartu Keluarga

$$
\begin{aligned}
& =\left(-\frac{2}{4} * \log 2\left(\frac{2}{4}\right)\right)+\left(-\frac{2}{4} * \log 2\left(\frac{2}{4}\right)\right) \\
& =-1
\end{aligned}
$$

c. Entropy Sim

$$
\begin{aligned}
& =\left(-\frac{4}{4} * \log 2\left(\frac{4}{4}\right)\right)+\left(-\frac{0}{4} * \log 2\left(\frac{0}{4}\right)\right) \\
& =0
\end{aligned}
$$

d. Entropy Paspor

$$
\begin{aligned}
& =\left(-\frac{1}{2} * \log 2\left(\frac{1}{2}\right)\right)+\left(-\frac{1}{2} * \log 2\left(\frac{1}{2}\right)\right) \\
& =1
\end{aligned}
$$

2. Menghitung nilai Entropy jumlah pinjaman

a. Nilai atribut Besar

$$
\begin{aligned}
& =\left(-\frac{2}{6} * \log 2\left(\frac{2}{6}\right)\right)+\left(-\frac{4}{6} * \log 2\left(\frac{4}{6}\right)\right) \\
& =0.089967
\end{aligned}
$$

b. Nilai atribut Sedang

$$
=\left(-\frac{4}{8} * \log 2\left(\frac{4}{8}\right)\right)+\left(-\frac{4}{8} * \log 2\left(\frac{4}{8}\right)\right)
$$

c. Nilai Atribut Kecil

$$
\begin{aligned}
& =\left(-\frac{-1}{1} * \log 2\left(\frac{1}{1}\right)\right)+\left(-\frac{-0}{1} * \log 2\left(\frac{0}{1}\right)\right) \\
& =0
\end{aligned}
$$

3. Menghitung nilai Entropy Jumlah Penghasilan

a. Nilai atribut Besar

$$
\begin{aligned}
& =\left(-\frac{-3}{3} * \log 2\left(\frac{3}{3}\right)\right)+\left(-\frac{-0}{3} * \log 2\left(\frac{0}{3}\right)\right) \\
& =0
\end{aligned}
$$

b. Nilai atribut Sedang

$$
\begin{aligned}
& =\left(-\frac{4}{9} * \log 2\left(\frac{4}{9}\right)\right)+\left(-\frac{5}{9} * \log 2\left(\frac{5}{9}\right)\right) \\
& =0.028771
\end{aligned}
$$

c. Nilai Atribut Kecil

$$
\begin{aligned}
& =\left(-\frac{-0}{2} * \log 2\left(\frac{0}{2}\right)\right)+0\left(-\frac{-2}{2} * \log 2\left(\frac{2}{2}\right)\right) \\
& =0
\end{aligned}
$$

4. Menghitung nilai Entropy Jenis Usaha

a. Nilai atribut Kuliner

$$
\begin{aligned}
& =\left(-\frac{-3}{5} * \log 2\left(\frac{3}{5}\right)\right)+\left(-\frac{-2}{5} * \log 2\left(\frac{2}{5}\right)\right) \\
& =-0.942179
\end{aligned}
$$

b. Nilai atribut Desain

$$
\begin{aligned}
& =\left(-\frac{2}{4} * \log 2\left(\frac{2}{4}\right)\right)+\left(-\frac{2}{4} * \log 2\left(\frac{2}{4}\right)\right) \\
& =-1
\end{aligned}
$$

c. Nilai atribut Bisnis

$$
\begin{aligned}
& =\left(-\frac{-1}{3} * \log 2\left(\frac{1}{3}\right)\right)+\left(-\frac{-2}{3} * \log 2\left(\frac{2}{3}\right)\right) \\
& =0.078910
\end{aligned}
$$

d. Nilai atribut Grosir

$$
=\left(-\frac{-1}{2} * \log 2\left(\frac{1}{2}\right)\right)+\left(-\frac{-1}{2} * \log 2\left(\frac{1}{2}\right)\right)
$$


$=1$

e. Nilai atribut Fotocopy

$$
\begin{aligned}
& =\left(-\frac{-0}{1} * \log 2\left(\frac{0}{1}\right)\right)+\left(-\frac{-1}{1} * \log 2\left(\frac{1}{1}\right)\right) \\
& =0
\end{aligned}
$$

5. Menghitung nilai Entropy Agunan

a. Nilai atribut BPKB

$$
\begin{aligned}
& =\left(-\frac{-1}{2} * \log 2\left(\frac{1}{2}\right)\right)+\left(-\frac{-1}{2} * \log 2\left(\frac{1}{2}\right)\right) \\
& =1
\end{aligned}
$$

b. Nilai atribut Surat Izin Usaha

$$
\begin{aligned}
& =\left(-\frac{-2}{3} * \log 2\left(\frac{2}{3}\right)\right)+\left(-\frac{-1}{3} * \log 2\left(\frac{1}{3}\right)\right) \\
& =1
\end{aligned}
$$

c. Nilai atribut Surat Tanah

$$
\begin{aligned}
& =\left(-\frac{-1}{2} * \log 2\left(\frac{1}{2}\right)\right)+\left(-\frac{-0}{1} * \log 2\left(\frac{0}{1}\right)\right) \\
& =0
\end{aligned}
$$

d. Nilai atribut Emas

$$
\begin{aligned}
& =\left(-\frac{-1}{3} * \log 2\left(\frac{1}{3}\right)\right)+\left(-\frac{-2}{3} * \log 2\left(\frac{2}{3}\right)\right) \\
& =0.078910
\end{aligned}
$$

e. Nilai atribut Sertifikat Rumah

$$
\begin{aligned}
& =\left(-\frac{-2}{3} * \log 2\left(\frac{2}{3}\right)\right)+\left(-\frac{-1}{3} * \log 2\left(\frac{1}{3}\right)\right) \\
& =0.078910
\end{aligned}
$$

6. Gain (Berkas)

$$
\begin{aligned}
& \left.\left.\left.\left.=0.5856817682-\left(\left(\frac{5}{15}\right) * 0.721885\right)\right)+\left(\left(\frac{4}{15}\right) * 1\right)\right)+\left(\left(\frac{4}{15}\right) * 0\right)\right)+\left(\left(\frac{2}{15}\right) * 1\right)\right) \\
& =0.5856817682-0.424095 \\
& =0.747266
\end{aligned}
$$

7. Gain (Jumlah Pinjaman)

$$
\begin{aligned}
& \left.\left.\left.=0.5856817682-\left(\left(\frac{6}{15}\right) * 0.089967\right)\right)+\left(\left(\frac{8}{15}\right) * 1\right)\right)+\left(\left(\frac{1}{15}\right) * 0\right)\right) \\
& =0.5856817682-0.569286 \\
& =0.016395
\end{aligned}
$$

8. Gain jumlah (Penghasilan)

$\left.\left.\left.=0.5856817682-\left(\left(\frac{3}{15}\right) * 0\right)\right)+\left(\left(\frac{9}{15}\right) * 0.028771\right)\right)+\left(\left(\frac{2}{15}\right) * 0\right)\right)$

$$
\begin{aligned}
& =0.5856817682-0.017262 \\
& =0.568418
\end{aligned}
$$

9. Gain (Jenis Usaha)

$$
\begin{aligned}
& \left.\left.\left.\left.\left.=0.5856817682-\left(\left(\frac{5}{15}\right) * 0.942179\right)\right)+\left(\left(\frac{4}{15}\right) * 1\right)\right)+\left(\left(\frac{3}{15}\right) * 0.078910\right)\right)+\left(\left(\frac{2}{15}\right) * 1\right)\right)+\left(\left(\frac{1}{15}\right) * 0\right)\right) \\
& =0.5856817682- \\
& =0.01086
\end{aligned}
$$

10. Gain (Agunan)

$$
\begin{aligned}
& \left.\left.\left.\left.\left.\quad=0.5856817682-\left(\left(\frac{2}{15}\right) * 1\right)\right)+\left(\left(\frac{3}{15}\right) * 1\right)\right)+\left(\left(\frac{1}{15}\right) * 0\right)\right)+\left(\left(\frac{3}{15}\right) * 0.078910\right)\right)+\left(\left(\frac{3}{15}\right) * 0.078910\right)\right) \\
& =0.5856817682-0.428025 \\
& =-0.157656
\end{aligned}
$$

Setelah seluruh nilai Entropy dan Gain diperoleh dari sampel yang dimiliki, berikut ini adalah rekapitulasi perhitun0gan nilai Entropy dan Gainnya. 


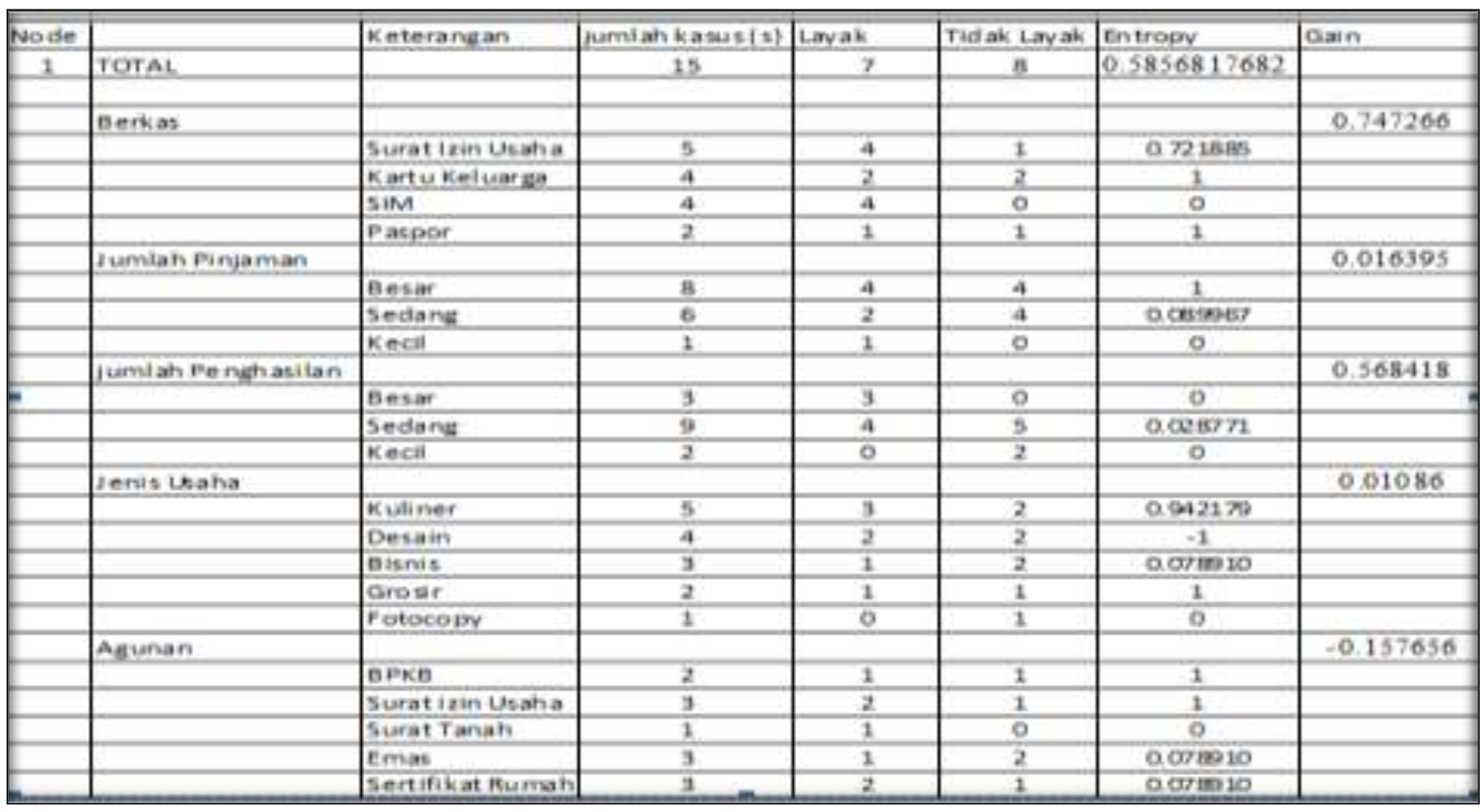

Gambar 4. Rekapitulasi Hasil

Gambar diatas menunjukkan bahwasanya kriteria letak daerah dampak memiliki nilai Gain yang paling tinggi. Untuk fase selanjutnya adalah pembentukan Tree (pohon keputusan). Berikut ini adalah Tree dari rekapitulasi nilai Entropy dan Gainnya.

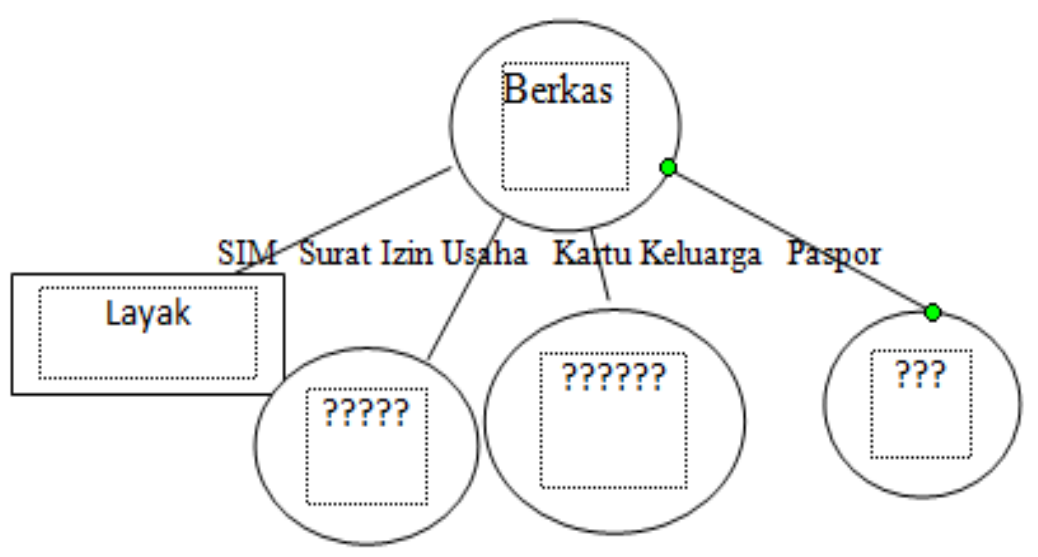

Gambar 5. Node

Karena pohon keputusan belum terlihat keseluruhan hasilnya sehingga kita perlu untuk mencari kembali Nilai Gain dan Entropy selanjutnya seperti dibawah ini:

Tabel 3. Atribut Paspor

\begin{tabular}{|c|c|c|c|c|c|c|c|c|c|}
\hline \multicolumn{10}{|c|}{ Data Nassabah Pengajuan UMKM Pada Produk Krasida } \\
\hline \multicolumn{10}{|c|}{ PT. Pegadaian UPC Kampung Durian } \\
\hline \multicolumn{10}{|c|}{ Pada Tahun 2018} \\
\hline No & $\begin{array}{l}\text { Nama } \\
\text { Usaha }\end{array}$ & Berkas & $\begin{array}{c}\text { Jumlah } \\
\text { Pinjaman }\end{array}$ & Penghasilan/bln & $\begin{array}{c}\text { Jenis } \\
\text { Usaha }\end{array}$ & Agunan/Jaminan & Produk & Keputusan & $\begin{array}{l}\text { Status } \\
\text { Usaha }\end{array}$ \\
\hline 6 & $\begin{array}{l}\text { Coffe } \\
\text { Jogal }\end{array}$ & PASPOR & Sedang & Sedang & Kuliner & Sertifikat Rumah & Krasida & Diterima & Aktif \\
\hline 13 & $\begin{array}{l}\text { Glend's } \\
\text { Bordir }\end{array}$ & PASPOR & Besar & Sedang & Desain & Surat Izin Usaha & Krasida & Tolak & Aktif \\
\hline
\end{tabular}

Langkah selanjutnya menghitung nilainya, berikut ini adalah rekapitulasi nilai entropy dan gainnya.

Tabel 4. Rekapitulasi Hasil

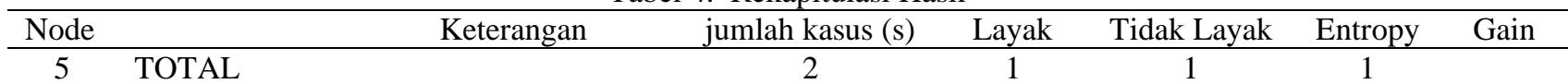


Jumlah Pinjaman

\begin{tabular}{|c|c|c|c|c|c|c|}
\hline \multirow{3}{*}{ 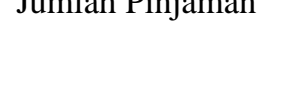 } & & & & & & \\
\hline & Besar & 1 & 1 & 0 & 0 & \multirow[b]{3}{*}{0} \\
\hline & Sedang & 1 & 0 & 1 & 0 & \\
\hline \multirow[t]{2}{*}{ jumlah Penghasilan } & & & & & & \\
\hline & Sedang & 2 & 1 & 1 & 1 & \\
\hline \multirow[t]{3}{*}{ Jenis Usaha } & & & & & & 1 \\
\hline & Desain & 1 & 1 & 0 & 0 & \\
\hline & Kuliner & 1 & 0 & 1 & 0 & \\
\hline \multirow[t]{3}{*}{ Agunan } & & & & & & 1 \\
\hline & Surat Izin Usaha & 1 & 1 & 0 & 0 & \\
\hline & Sertifikat rumah & 1 & 0 & 1 & 0 & \\
\hline
\end{tabular}

Tabel diatas menunjukkan bahwasanya kriteria letak daerah dampak memiliki nilai Gain yang paling tinggi. Untuk fase selanjutnya adalah pembentukan Tree (pohon keputusan). Berikut ini adalah Tree dari rekapitulasi nilai Entropy dan Gainnya.

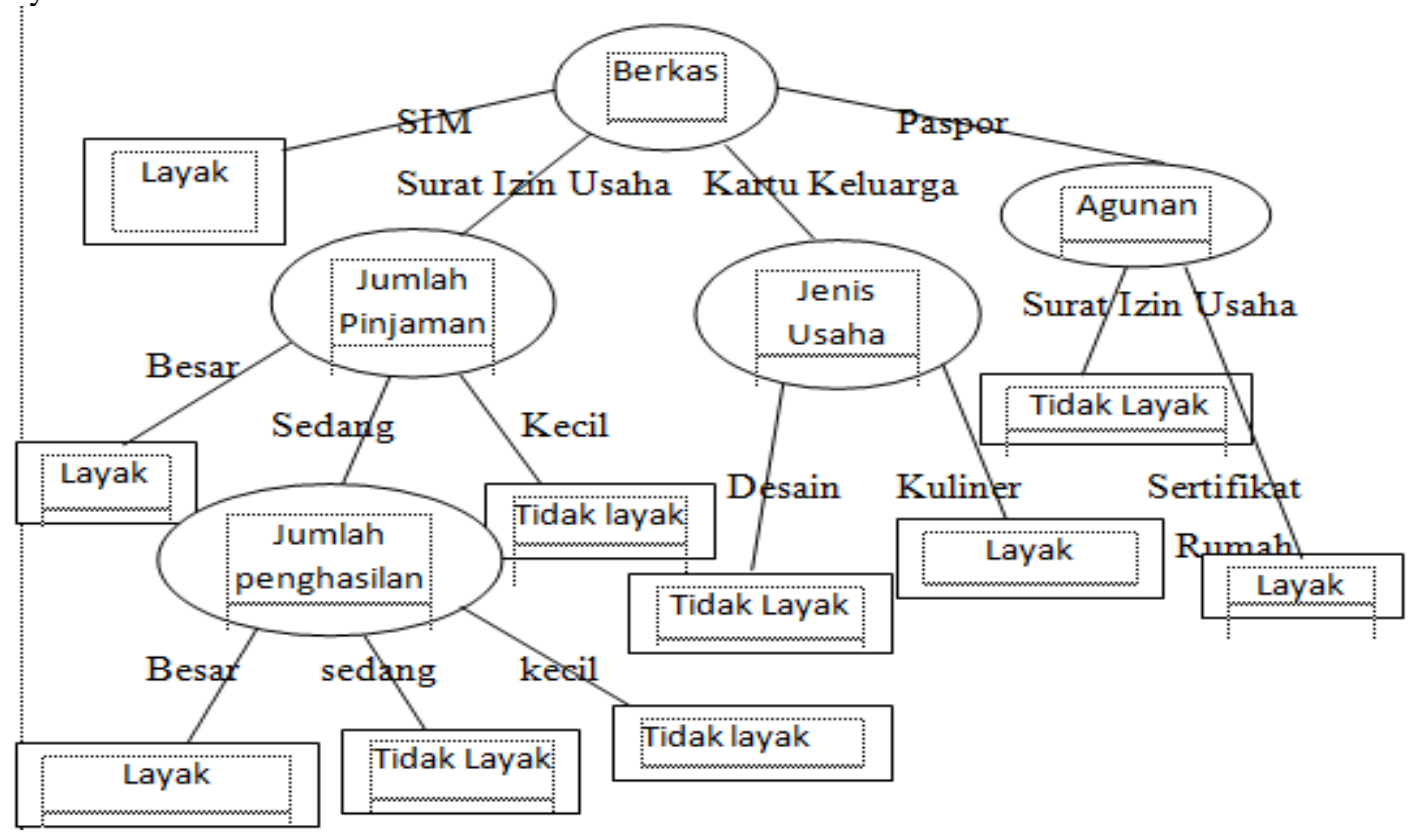

Gambar 6. Node Keputusan

Maka basis pengetahuan atau rule yang terbentuk yaitu:

1. Jika memiliki berkas $=$ SIM maka Hasil Pengajuan $=$ Layak Diterima

2. Jika Jumlah pinjaman = besar, dan kecil = maka Hasil pengajuan = tidak layak diterima

3. Jika Jumlah pinjaman = sedang = maka Hasil pengajuan dengan jumlah penghasilan besar $=$ layak diterima

4. Jika Jumlah pinjaman $=$ sedang = maka Hasil pengajuan dengan jumlah pinjaman sedang dan kecil = tidak layak diterima

5. Jika Berkas $=$ Kartu keluarga dan Jenis Usaha =Desain Dan Kuliner maka Hasil= Layak diterima

6. Jika Berkas $=$ Paspor $=$ sertifikat rumah=maka Hasil Layak Diterima

7. Jika Berkas $=$ Paspor $=$ Surat izin Usaha $=$ maka Hasil tidak Layak Diterima

Dari pohon keputusan diatas dapat disimpulkan bahwa pengajuan proposal untuk mendapatkan produk krasida dengan berkas SIM maka proposal pengajuan menjadi layak. Kemudian jika berkas dengan jumlah pinjaman dengan kategori Besar dan kecil, pengajuan tidak layak diterima, pengajuan dengan berkas, jumlah pinjaman dan penghasilan perbulan besar makan pengajuan layak diterima, dengan sedang dan kecil pengajuan tidak layak diterima. Pada note ketiga jika berkas diajukan dengan berkas kartu keluarga dengan berkas jenis usaha desain dan kuliner maka hasil akan layak diterima. Pada kondisi lain jika berkas Paspor dengan Surat izin Usaha dan Sertifikat Rumah layak diterima dalam penganjuan UMKM Produk krasida.

\section{KESIMPULAN}

Dari uraian bab demi bab dapat diambil kesimpulan sebagai berikut:

1. Menentukan kelayakan UMKM untuk mendapatkan program Krasida

2. Analisa data UMKM yang dilakukan secara manual, memproses data lama dan kurang efisien dibandingkan dengan analisa data dengan metode J48. 
3. Dengan aplikasi Weka pemenuhan akan kebutuhan informasi bagi sistem yang terkait agar pengolahan analisa data cepat, tepat, hemat, akurat maka diperlukan adanya integrasi sistem dengan menerapkan teknologi yang sesuai dengan kemampuan dan kebutuhan.

\section{REFERENCES}

[1] Fajar Astuti Hermawati, Data Mining, I ed., Putri Cristian, Ed. Yogyakarta, Yogyakarta: Offset ANDI, 2013.

[2] Emha Taufiq Luthfi and Kusrini, Algoritma Data Mining, I ed., Theresia Ari Prabawati, Ed. Yogyakarta, Yogyakarta: ANDI OFFSET, 2009.

[3] Sanni Susanto and Dedy Suryadi, Pengantar Data Mining- Menggali Pengetahuan Dari bongkahan Data, I ed., Nikodemus WK, Ed. Yogyakarta, Yogyakarta: ANDI OFFSET, 2010.

[4] MBA,Akt Frof.Dr.Jogiyanto HM, Analisis dan Desain, III ed. Yogyakarta, Yogyakarta: ANDI OFFSET, 1990,1999,2005.

[5] Dr.Ir.Eddy Soeryanto Soegoto, Enterpreneurship-Menjadi Pebisnis Ulung, I ed., Rayendra L Toruan, Ed. Jakarta, Jakarta: Kompas GRAMEDIA, 2009.

[6] Philip Kotler and Kevin Lane Keller, Marketing manajement, VII ed. USA, USA: Grada Publishing, 2013.

[7] Mukhhammad Yunan Helmi, Drs. Kushartanta M Ikop, and Nurdin Bahtiar S.Si.M.t, "Implementasi Data Mining untuk memprediksi Kelayakan permintaan Nassabah," Informatic dan Tehnologi, vol. 2, pp. 33-42, 2013.

[8] Edhy Sutanta, Pengantar Teknologi Informasi, V ed. Yogyakarta, Yogyakarta: GRAHA ILMU, 2005.

[9] M.Kom., Drs.Lamhot Sitorus, Algoritma Dan Pemrograman, I ed., Arie Pramesta, Ed. Yogyakarta, Yogyakarta: ANDI OFFSET, 2015.

[10] Sigit Adinugroho and Yuita Arum Sari, Implementasi Data Mining Menggunakan Weka, I ed., Saiful Nur Budiman, Ed. Malang, Malang: UB Press, 2018.

[11] Mardiana Wati, 6 Jam Belajar Sendiri Microsoft office Excel 2007, I ed. Bandung, Bandung: CV.YRAMA WIDYA, 2008. 